\title{
Pathologic Genomic Rearrangements in Idiopathic Mentally Retarded Patients from Iran
}

Farzane Bahari ${ }^{1,3}$, Mohammad Taghi Akbari ${ }^{1-3^{*}}$, Fatemeh Omrani Tabarestani ${ }^{4,3}$, Faravareh Khordadpoor Deilamani ${ }^{5,3}$, Gholam Reza Babamohamadi ${ }^{3}$, Shokouholsadat Mahdavi ${ }^{3}$ and Shohre Zare Karizi ${ }^{6,3}$

${ }^{1}$ University of Guilan, Rasht, Iran

${ }^{2}$ Department of Medical Genetics, Tarbiat Modares University, Tehran, Iran

${ }^{3}$ Tehran Medical Genetics Laboratory, Tehran, Iran

${ }^{4}$ Department of Biology, Islamic Azad University, Tabriz, Iran

${ }^{5}$ Department of Biology, Islamic Azad University, Tehran, Iran

${ }^{6}$ Deparment of Biology, Islamic Azad University, Varamin Pishva, Iran

*Corresponding author: Mohammad Taghi Akbari, Department of Medical Genetics, Faculty of Medical Sciences, Tarbiat Modares University, P.O. Box: 14115-331, Tehran 9821, Iran, Tel: 88896868-9; Fax: 88896869; E-mail: mtakbari@modares.ac.ir

Received date: May 27, 2015; Accepted date: June 16, 2015; Published date: June 20, 2015

Copyright: $\odot 2015$ Bahari F, et al. This is an open-access article distributed under the terms of the Creative Commons Attribution License, which permits unrestricted use, distribution, and reproduction in any medium, provided the original author and source are credited.

\begin{abstract}
Background: Mental retardation is a relatively frequent disorder and occurs in 1-3\% of the general population. Chromosomal rearrangements involving microdeletion and microduplication particularly in subtelomeric regions are involved as a significant cause of idiopathic mental retardation. This study was designed to detect these aberrations in the Iranian patients with idiopathic mental retardation.

Seventy six patients with unexplained MR, a normal conventional karyotype and negative for fragile $\mathrm{X}$ without a clinically recognizable syndrome were included in our study. We used a combination of MLPA kits procured from MRC Holland to increase the detection rate of chromosomal abnormalities in idiopathic MR patients. These kits included P036 and P070 for subtelomeric screening, and in addition P064 and P096 for the 16 common microdeletion syndromes.
\end{abstract}

Results: The MLPA analysis revealed chromosomal aberrations in 8 cases.

Conclusion: Using the combination of four MLPA kits the rate of chromosomal abnormality detection in our study was $10.52 \%$ which confirms the previous published findings.

Keywords: Intellectual Disability; Genomic rearrangement; Iran

\section{Introduction}

Mental retardation (MR) is a variable, heterogeneous manifestation of central nervous system dysfunctions, occurring in $1-3 \%$ of general population $[1,2]$. MR etiology is very heterogeneous and unfortunately, in about more than half the cases the cause of MR is still elusive [3]. Causes of mental retardation are numerous and include genetic and environmental factors [4]. Anything that damages and interferes with the growth and maturation of the brain can lead to MR, and this might happen before, during or after the birth of the child [1, $3]$. Though it is generally assumed that half of the cases are due to genetic factors, the cause of the handicap in up to $50 \%$ of patients remains unexplained [5]. Chromosomal aberrations are the most common cause of mental retardation and it is estimated that $4-36 \%$ of moderate to severe mental retardations are due to chromosomal aberrations [6]. The detection rate of chromosomal abnormalities in patients with MR and dysmorphic features has increased due to the improvements of molecular cytogenetic methods. Cytogenetic analysis by conventional G-banding is the standard method of investigating chromosomal abnormalities but this technique cannot detect small structural abnormalities $(<4 \mathrm{Mb})$. Smaller chromosomal abnormalities can be identified with array techniques, fluorescent in situ hybridization (FISH) or multiplex ligation-dependent probe amplification (MLPA) techniques [7-10]. In this study we investigated further molecular basis of the Iranian patients with idiopathic MR who had normal karyotype and were negative for fragile X syndrome for subtelomeric rearrangements and common microdeletion/ microduplication syndromes.

\section{Materials and Methods}

\section{Patients:}

A total of 76 unrelated individuals with unexplained congenital MR or developmental delay who werereferred to Tehran Medical Genetics Laboratory by clinical neurologists were recruited to this study with written consent from their parents or guardians. The study was also approved by local university ethic committee. All but one of these patients was male. All were evaluated by a clinical geneticist and had a normal $\mathrm{G}$ banded karyotype at 550 band level, and did not have Fragile $\mathrm{X}$ and no clinical syndrome had been recognized initially. 
Citation: Bahari F, Akbari MT, Tabarestani FO, Deilamani FK, Babamohamadi GR, et al. (2015) Pathologic Genomic Rearrangements in Idiopathic Mentally Retarded Patients from Iran. J Neurol Neurophysiol 6: 296. doi:10.4172/2155-9562.1000296

Page 2 of 5

\section{DNA extraction, MLPA analysis, array CGH and FISH technique:}

Genomic DNA was extracted from peripheral blood using salting out procedure. All patients were screened for subtelomeric rearrangements using P036, P070 SALSA MLPA kits and microdeletion/microduplication syndromes using P064 MR1 and P096 MR2 kits following the standard procedures recommended by the MRC Holland. ABI 3130 Genetic Analyzer was used for separation of amplification products and Gene marker software (version 1.85) was used for the data analysis.

One of the samples was previously tested by the array CGH using Agilent platform by Oxford Gene Technology (OGT) company and
Cytosure interpret software was used to analyze the data. MLPA was applied to confirm the findings in the patient and his parents.

For one patient, Fluorescence In Situ Hybridization (FISH) was performed using Prader-Willi/Angelmanregion probe and $15 \mathrm{q}$ subtelomere specific probe following the protocol recommended by Cytocell aqurius company.

\section{Results}

MLPA method revealed abnormalities in 8 out of 76 patients. This is $10.52 \%$ detection rate which is consistent with other investigations $[11,12]$. The results are summarized in Table 1 , and in the following each case is described separately.

\begin{tabular}{|c|c|c|c|c|c|c|}
\hline \multirow[t]{2}{*}{ Patient } & \multirow[t]{2}{*}{ Age/ Sex } & \multirow[t]{2}{*}{ Karyotype } & \multicolumn{2}{|c|}{ Subtelomeric MLPA kits } & \multicolumn{2}{|c|}{ Syndromic MLPA kits } \\
\hline & & & P036 & P070 & P064 & P096 \\
\hline P1 & $11 / \mathrm{M}$ & Normal & Dup $4 p$ and del $9 p$ & Dup $4 p$ and del $9 p$ & Normal & Dup 4p16.3 \\
\hline P2 & $8 / \mathrm{M}$ & Normal & Del $18 p$ and dup5p & Del $18 p$ and dup5p & Normal & Dup5p15 \\
\hline P3 & $33 / \mathrm{M}$ & Normal & Del 22q & Del 22q & Normal & Normal \\
\hline P4 & $32 / \mathrm{M}$ & Normal & Dup4q & Dup4q & Normal & Normal \\
\hline P5 & 9/M & Normal & Del 15q-cen & Del 15q-cen & Del15q11.2 & Normal \\
\hline P6 & $7 / \mathrm{M}$ & Normal & Normal & Normal & Dup 17p11.2 & Normal \\
\hline P7 & $30 / F$ & Normal & Dup 3p & Dup 3p & Normal & Normal \\
\hline P8 & $14 / \mathrm{M}$ & Normal & Del 18p & Del 18p & Normal & Normal \\
\hline
\end{tabular}

Table 1: Overview of the detected abnormalities found in patients with four sets of MLPA kits P036, P070, P064, and P096.

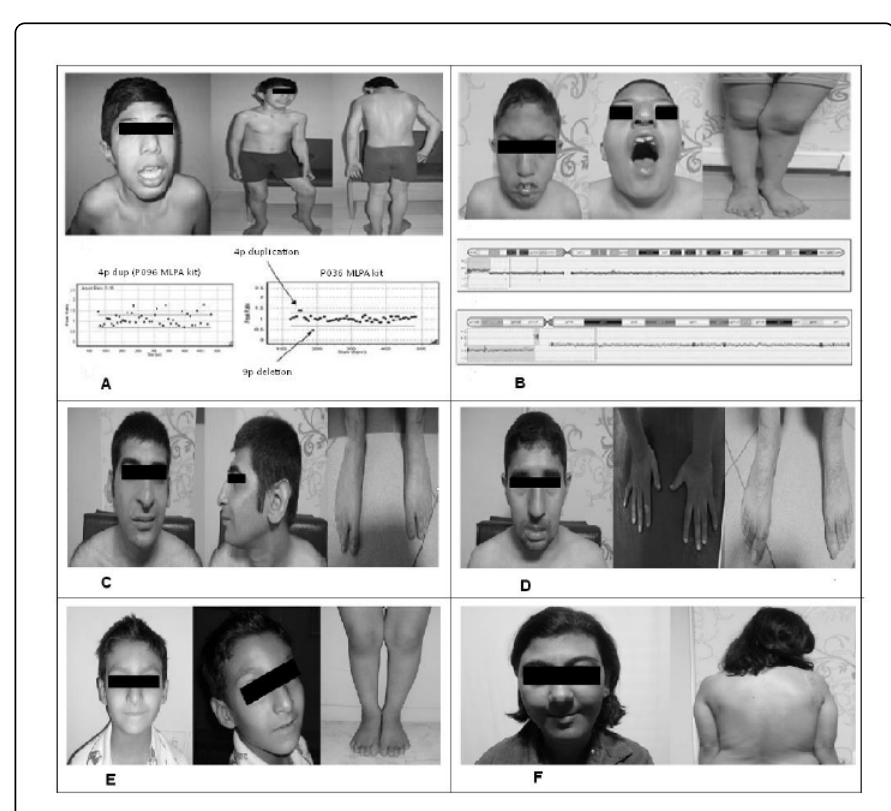

Figure A-F: Patient 1, B: patient 2, C: patient 3, D: patient 4, E: Patient 6, F: Patient 7

\section{Patient 1}

The patient had severe MR, seizure and facial dysmorphism, hypertelorism, microphthalmia, broad nasal bridge, short upper lip, down turned corners of the mouth, low hairline, high arched eyebrows, chest deformity and scoliosis (Figure A). MLPA testing detected duplication of $4 \mathrm{p}$ and deletion of $9 \mathrm{p}$. Karyotypes and MLPA results of the patient's parents were normal. Therefore the observed structural rearrangements can be considered denovo.

\section{Patient 2}

He had MR, speech delay, dermatitis, macrocephaly, round face, low hair line, broad cheeks, prominent maxilla, hypertlorism, upslanting palpebral fissures, retrognathia, epicanthic folds, glaucoma/ buphthalmos, broad nasal bridge, abnormal nasal septum, small and downturned mouth, thick lips, high vaulted and narrow palate, tooth crown shape abnormality, oligodontia, dental caries, flat philtrum, posterior angulation of ears, anteverted/ bat ears, ear lobe abnormal size, short neck, umbilical hernia, inguinal hernia, scoliosis, lordosis, large hand, small penis, coxavara, coloboma of the eyelid, abnormally placed nipples, umbilical hernia, mild arachnodactyly, large foot, overlapping toes and knock knees- genu valgum (Figure B).

This patient was previously studied by the array CGH and three aberrations were observed (Figure B) which were suspicious to be pathogenic according to the databases such as DGV, CHOP CNV and decipher (https://decipher.sanger.ac.uk/)). These aberrations and their 
features are summarized in Table 2. There are some reported patients with chromosomal aberrations similar to this patient who are suffering from mental retardation and have other features some of which are in common with our patient

As a confirmatory test, MLPA was carried out for this patient and his parents. The first and second aberrations (Table 2) which are gain and loss of large segments of chromosome $5 p$ and $18 p$ respectively were completely consistent with the MLPA results. The patient's parents were normal for these regions. Therefore these aberrations were de novo and most probably the cause of MR in this patient. We didn't have any MLPA kit to study the third aberration which was a small gain of chromosome $18 \mathrm{p}$ in more detail.

\begin{tabular}{|l|l|l|l|}
\hline Aberration & $\mathbf{1}$ & $\mathbf{2}$ & $\mathbf{3}$ \\
\hline Cytogenetic Location & $5 \mathrm{p} 15.2-5 \mathrm{p} 15.33$ & $18 \mathrm{p} 11.21-18 \mathrm{p} 11.32$ & $18 \mathrm{p} 11.21$ \\
\hline Gain/Loss & Gain & Loss & Gain \\
\hline Start-Stop & $75149-10097255$ & $139089-12869768$ & $12974229-14071934$ \\
\hline Size & $10.022 \mathrm{Mb}$ & $12.731 \mathrm{Mb}$ & $1.098 \mathrm{Mb}$ \\
\hline \# probes & 231 & 231 & 46 \\
\hline Syndrome Region & Cri du Chat (5p deletion) & Holoprosencephaly 4 & 12 \\
\hline \# genes & 69 & 108 & 1 \\
\hline \# OMIM genes & 6 & 2 & 1 \\
\hline OMIM genes & MTRR, SLC6A3, TERT, SLC6A19, NDUFS6, & NDUFV2, LPIN2 & MC2R \\
\hline
\end{tabular}

Table 2: The aberrations found by Array CGH test in patient 2

\section{Patient 3}

He had severe MR and facial dismorphism, delayed speech, dolichocephaly, hypotelorism, wide eyebrow, long eyelashes, high arched palate, abnormal tooth position, large, prominent and posterior angulations of ear, broad thumb, sandal gap, large fleshy hands, cardiac defect and autism (Figure C). Deletion of 22q subtelomeric region was detected by MLPA method.

\section{Patient 4}

He had mild MR, structural asymmetry of face, prominent forehead, hypertelorism, beaked nose, high arched palate, short neck, scoliosis, mildly tapered fingers, proximally set thumb, gynaecomastia and broad thumb (Figure D). MLPA testing revealed duplication in the $4 \mathrm{q}$ subtelomeric region.

\section{Patient 5}

The DNA sample of this MR patient with a normal karyotype was referred to our laboratory. MLPA testing indicated heterozygous deletions in 15q11.2 which suggested the probability of the Angelman/ Prader-Willi syndrome.

The FISH technique was performed for this patient using SNRPN/IC probe and a $15 \mathrm{q}$ subtelomere probe as a control which were applied on metaphase nuclei. Deletion of $15 q$ was confirmed.

\section{Patient 6}

He had MR, hyperactivity, unusual onychotillomania, polyembolokoilamania, head banging, sleep apnea and autism. He had a characteristic craniofacial appearance and prominent forehead (Figure E). MLPA testing showed 17p11.2 duplication.

\section{Patient}

She had mild MR, squareface, broad cheeks, high cheek bones, hypotelorism, down -slanting palpebral fissures, epicanthic folds, flatend nose, deeply grovedphiltrum, narrow palate, deeply eruption of teeth, low set ears, abnormally placed nipples, hypoplastic nipples, kyphosis, lumbarlordosis, scoliosis, affected facial nerve, low hair line and epilepsy (Figure F). MLPA method displayed duplication in $3 p$ subtelomeric region.

\section{Patient}

We could not examine the characteristic features of this MR patient. MLPA revealed 18p deletion in her genome.

\section{Discussion}

The detection rate of chromosomal abnormalities in idiopatic mentally retarded individuals has increased due to the improving resolution of molecular cytogenetic techniques [13]. Many studies have shown that subtelomeric aberrations are significant cause of 5 to $10 \%$ of idiopathic moderate to severe mental retardation $[11,12]$. MLPA screening based on the SALSA P036, P070, P064 and P096 kits was performed in this study. We detected genomic abnormalities in 8 out of $76(10.52 \%)$ patients with unexplained MR.

In patient 1 , combination of symptoms of both $4 \mathrm{p}$ duplication and $9 p$ deletion syndromes were present. Genes such as TACC3, LETM1 and FGFR3 which are involved in duplicated region may have roles in the patient phenotype such as Seizure and skeletal abnormalities [14-18]. As far as $9 p$ deletion is concerned, patients with $9 p$ deletion present with MR, craniofacial dysmorphic features and genital or gonadal disorders [19-21]. 
Although patient 2 had normal karyotype, the detected aberrations by array CGH approach revealed the rearrangement of large segments of chromosomal material. It can be argued that since the gained and lost segments were almost of equal sizes, an exchange of material in the germline has taken place between chromosomes $5 \mathrm{p}$ and $18 \mathrm{p}$ in the form of reciprocal translocation.

The 22q13 deletion syndrome (or Phelan-McDermid syndrome) is a microdeletion syndrome characterized by severe neonatal hypotonia and global developmental delay, normal to accelerated growth, absent to severely delayed speech and minor dysmorphic features. Of the more than 90 genes that may be deleted in 22q13.3 deletion syndrome (Phelan-McDermid syndrome), the majority of the neurological features are thought to be caused by haploinsufficiency of SHANK3 [22] which is deleted in patient 3 too.

$4 \mathrm{q}$ duplication is a rare condition that usually presents with MR and multiple abnormalities, including microcephaly, malformed ears, flat nasal bridge, tooth and thumb anomalies [23, 24], most of which are shared by patient 4 .

Patient 6 had 17p11.2 duplication (Potocki-Lupski syndrome). Deletion and duplication of the $3.7-\mathrm{Mb}$ region in $17 \mathrm{p} 11.2$ result in two reciprocal syndromes, Smith-Magenis syndrome (SMS, OMIM \#182290) and Potocki-Lupski syndrome (PTLS, OMIM \#610883) respectively which arise through a faulty non allelic homologous recombination $[25,26]$. The clinical features observed in patients with PTLS are distinct from those seen with SMS although cognitive and neurobehavioral abnormalities are present in both disorders. Clinically, PTLS presents as a milder syndrome than SMS, with distinct characteristics, though PTLS can be mistaken for SMS [25-28].

Patients 7 and 8 showed subtelomeric chromosomal rearrangements. These regions are gene-rich and a small deletion in these regions results in severe consequences such as moderate to severe MR and multiple congenital anomalies, dysmorphism, and abnormal growth or behavior [12].

\section{Acknowledgments}

The authors thank the patients and their families for their collaboration and the neurologist clinicians who referred them for this study. The personnel of Tehran Medical Genetics Laboratory are acknowledged for their help and support. Esp. thanks to Miss M. Aryana for doing the FISH testing. This project was financially supported by Tehran Medical Genetics Laboratory, grant number 90001.

\section{References}

1. Galasso C, Lo-Castro A, El-Malhany N, Curatolo P (2010) "Idiopathic" mental retardation and new chromosomal abnormalities. Ital J Pediatr 36: 17.

2. Pereira RR, Pinto IP, Minasi LB, de Melo AV, da Cruz e Cunha DM, et al. (2014) Screening for intellectual disability using high-resolution CMA technology in a retrospective cohort from Central Brazil. PLoS One 9: e103117.

3. Bernardini L, Alesi V, Loddo S, Novelli A, Bottillo I, et al. (2010) Highresolution SNP arrays in mental retardation diagnostics: how much do we gain? Eur J Hum Genet 18: 178-185.

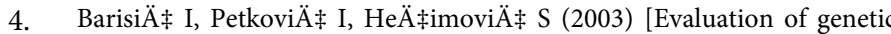
causes of mental retardation]. Lijec Vjesn 125: 71-77.

5. Rooms L, Reyniers E, van Luijk R, Scheers S, Wauters J, et al. (2004) Subtelomeric deletions detected in patients with idiopathic mental retardation using multiplex ligation-dependent probe amplification (MLPA). Hum Mutat 23: 17-21.

6. Hila L, Tébourbi H, Abaied L, Rejeb I, Ben Jemaa L, et al. (2009) MLPA subtelomere analysis in Tunisian mentally retarded patients. Biochem Genet 47: 727-733.

7. Mandal K, Boggula VR, Borkar M, Agarwal S, Phadke SR, et al. (2009) Use of Multiplex Ligation-Dependent Probe Amplification (MLPA) in screening of subtelomeric regions in children with idiopathic mental retardation. Indian J Pediatr 76: 1027-1031.

8. Northrop EL, Ren H, Bruno DL, McGhie JD, Coffa J, et al. (2005) Detection of cryptic subtelomeric chromosome abnormalities and identification of anonymous chromatin using a quantitative multiplex ligation-dependent probe amplification (MLPA) assay. Hum Mutat 26: 477-486.

9. John N, Rajasekhar M, Girisha KM, Sharma PS, Gopinath PM (2013) Multiplex ligation-dependant probe amplification study of children with idiopathic mental retardation in South India. Indian J Hum Genet 19: 165-170.

10. Tassano E, De Santis LR, Corona MF, Parmigiani S, Zanetti D, et al. (2015) Concomitant deletion of chromosome 16p13.11 and triplication of chromosome 19p13.3 in a child with developmental disorders, intellectual disability, and epilepsy. Mol Cytogenet 8: 9.

11. Koolen DA, Nillesen WM, Versteeg MH, Merkx GF, Knoers NV, et al. (2004) Screening for subtelomeric rearrangements in 210 patients with unexplained mental retardation using multiplex ligation dependent probe amplification (MLPA). J Med Genet 41: 892-829.

12. Lam AC, Lam ST, Lai KK, Tong TM, Chau TC (2006) High rate of detection of subtelomeric aberration by using combined MLPA and subtelomeric FISH approach in patients with moderate to severe mental retardation. Clin Biochem 39: 196-202.

13. Keren B, Le Caignec C (2011) Oligonucleotide microarrays in constitutional genetic diagnosis. Expert Rev Mol Diagn 11: 521-532.

14. Yao R, Natsume Y, Noda T (2007) TACC3 is required for the proper mitosis of sclerotome mesenchymal cells during formation of the axial skeleton. Cancer Sci 98: 555-562.

15. Cyr AB, Nimmakayalu M, Longmuir SQ, Patil SR, Keppler-Noreuil KM, et al. (2011) A novel 4p16.3 microduplication distal to WHSC1 and WHSC2 characterized by oligonucleotide array with new phenotypic features. Am J Med Genet A 155A: 2224-2228.

16. Nowikovsky K, Froschauer EM, Zsurka G, Samaj J, Reipert S, et al. (2004) The LETM1/YOL027 gene family encodes a factor of the mitochondrial $\mathrm{K}+$ homeostasis with a potential role in the Wolf-Hirschhorn syndrome. J Biol Chem 279: 30307-30315.

17. Hasegawa A and van der Bliek AM (2007) Inverse correlation between expression of the Wolfs Hirschhorn candidate gene Letm 1 and mitochondrial volume in C. elegans and in mammalian cells. Hum Mol Genet 16: 2061-2071.

18. Yaguchi Y, Yu T, Ahmed MU, Berry M, Mason I, et al. (2009) Fibroblast growth factor (FGF) gene expression in the developing cerebellum suggests multiple roles for FGF signaling during cerebellar morphogenesis and development. Dev Dyn 238: 2058-2072.

19. Barbaro M, Balsamo A, Anderlid BM, Myhre AG, Gennari M, et al. (2009) Characterization of deletions at $9 p$ affecting the candidate regions for sex reversal and deletion 9p syndrome by MLPA. Eur J Hum Genet 17: 1439-1447.

20. Hauge X, Raca G, Cooper S, May K, Spiro R, et al. (2008) Detailed characterization of, and clinical correlations in, 10 patients with distal deletions of chromosome 9p. Genet Med 10: 599-611.

21. Sirisena ND, Wijetunge UK, de Silva R, Dissanayake VH, et al. (2013) Child with deletion $9 \mathrm{p}$ syndrome presenting with craniofacial dysmorphism, developmental delay, and multiple congenital malformations. Case Rep Genet: 785830.

22. Phelan MC (2008) Deletion 22q13.3 syndrome. Orphanet J Rare Dis 3: 14. 
Citation: Bahari F, Akbari MT, Tabarestani FO, Deilamani FK, Babamohamadi GR, et al. (2015) Pathologic Genomic Rearrangements in Idiopathic Mentally Retarded Patients from Iran. J Neurol Neurophysiol 6: 296. doi:10.4172/2155-9562.1000296

Page 5 of 5

23. Celle L, Lee L, Rintoul N, Savani RC, Long W, et al. (2000) Duplication of chromosome region 4q28.3-qter in monozygotic twins with discordant phenotypes. Am J Med Genet 94: 125-140.

24. Assawamakin A, Wattanasirichaigoon D, Tocharoentanaphol C, Waeteekul S, Tansatit M, et al. (2012) A novel maternally-derived insertional translocation resulting in partial trisomy $4 \mathrm{q} 13.2-\mathrm{q} 22.1$ with complex translocation $\mathrm{t}(8 ; 20)$ in a family with intellectual disability. Am J Med Genet A 158A: 901-908.

25. Lee CG, Park SJ, Yun JN, Yim SY, Sohn YB (2012) Reciprocal deletion and duplication of 17p11.2-11.2: Korean patients with Smith-Magenis syndrome and Potocki-Lupski syndrome. J Korean Med Sci 27: 1586-1590.
26. Potocki L, Chen KS, Park SS, Osterholm DE, Withers MA, et al. (2000) Molecular mechanism for duplication 17p11.2- the homologous recombination reciprocal of the Smith-Magenis microdeletion. Nat Genet 24: 84-87.

27. Lee CG, Park SJ, Yim SY, Sohn YB (2013) Clinical and cytogenetic features of a Potocki-Lupski syndrome with the shortest $0.25 \mathrm{Mb}$ microduplication in 17p11.2 including RAI1. Brain Dev 35: 681-685.

28. Yusupov R, Roberts AE, Lacro RV, Sandstrom M, Ligon AH (2011) Potocki-Lupski syndrome: an inherited dup(17)(p11.2p11.2) with hypoplastic left heart. Am J Med Genet A 155A: 367-371. 